\title{
A Systematic Review on the Use of Bortezomib in Multiple Myeloma Patients with Renal Impairment: What Is the Published Evidence?
}

\author{
Eugenio Piro Stefano Molica \\ Department Hematology-Oncology, Azienda Ospedaliera Pugliese-Ciaccio, Catanzaro, Italy
}

\section{Key Words}

Bortezomib $\cdot$ Multiple myeloma $\cdot$ Renal impairment

\begin{abstract}
This report presents the totality of evidence through a systematic review that assessed either the efficacy or safety of bortezomib-based regimens in multiple myeloma with renal impairment. A systematic and comprehensive search of the literature was performed using MEDLINE databases from 1978 to December 1, 2010, and a hand search of references. We used the following medical subject headings (MESH) to identify potential studies: 'myeloma renal failure' $(1,225$ hits) and 'bortezomib' (2,554 hits). An additional search performed by combining the MESH terms 'myeloma renal failure' and 'bortezomib' yielded 50 citations. Five additional case-control studies judged relevant for the purpose of study were also included. In total, 6 case reports, 9 case series and 9 case-control studies were identified that reported on myeloma, renal failure and bortezomib. In this review, only the case series and case-control studies were considered. The results of our search led to the following conclusions: (1) bortezomib is feasible and well tolerated and its efficacy and safety are not substantially modified by renal failure patients, (2) renal failure should not induce physicians to reduce doses, since the efficacy of bortezomib is attained also in dialyzed patients who may achieve dialysis independence, and (3) standard doses of bortezomib (i.e. $1.3 \mathrm{mg} / \mathrm{m}^{2}$ on days
\end{abstract}

$1,4,8,11)$ associated with dexamethasone yield satisfactory tumor response, generally obtained shortly after starting therapy. Although many questions remain unanswered, our effort should be considered a relevant scientific and practical address for generating a diagnostic and therapeutic algorithm to be used in patients with renal impairment related to multiple myeloma.

Copyright $\odot 2011$ S. Karger AG, Basel

\section{Introduction}

Renal impairment (RI) is a common feature of multiple myeloma (MM) occurring in $20-40 \%$ of newly diagnosed patients. Furthermore, RI can evolve over time and an estimated $25-50 \%$ of patients are affected during the course of the disease [1]. Roughly $1-13 \%$ of patients require dialysis and an increased number of early deaths is associated with this condition $[1,2]$. In recent years, the prognosis of MM patients with RI has improved due to the availability of more effective treatments for MM and progress in supportive care. However, prognosis appears related to the reversibility of RI [3-5], although this has not been confirmed in all series [6].

Bortezomib is the first-in-class proteasome inhibitor with proven efficacy in both newly diagnosed and relapsed/refractory MM. In combination with either steroids or conventional chemotherapeutic agents, bortezo-

\section{KARGER}

Fax +41613061234 E-Mail karger@karger.ch www.karger.com

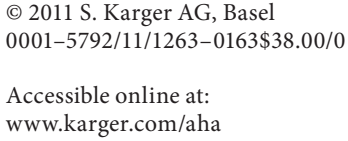

Stefano Molica, MD

Department Hematology-Oncology, Azienda Ospedaliera Pugliese-Ciaccio Viale Pio X

IT-88100 Catanzaro (Italy)

Tel. +39 0961883 001, E-Mail smolica@libero.it 


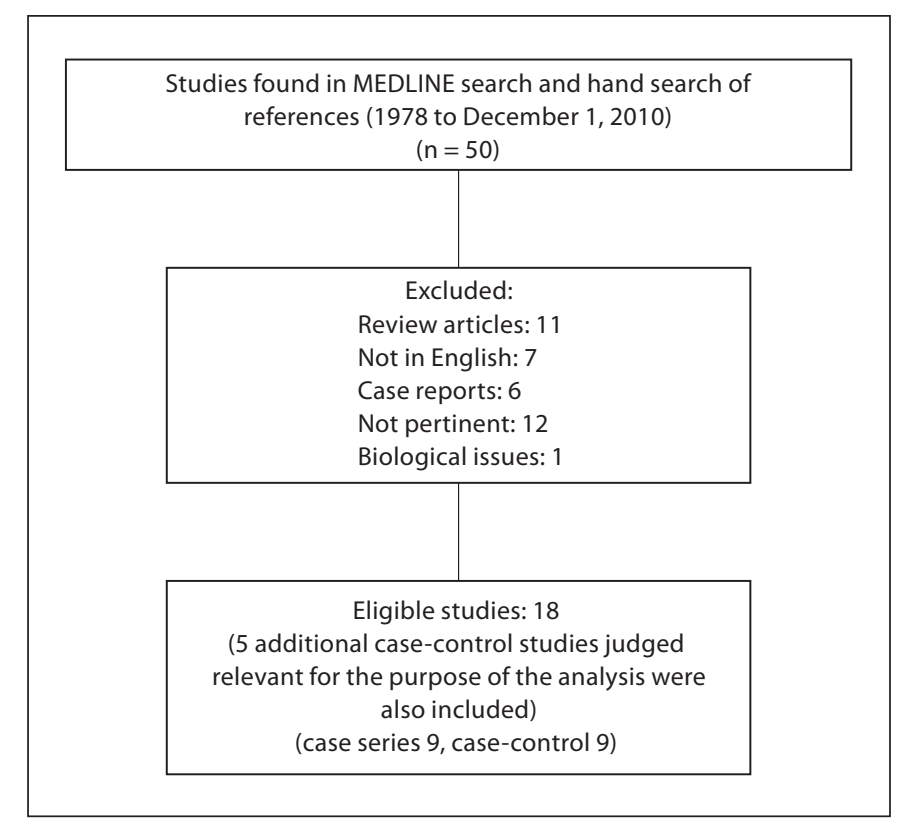

Fig. 1. Flow diagram representing the selection of studies.

mib demonstrated activity in patients with $\mathrm{MM}$ and RI [1-18].

To the best of our knowledge, data regarding the reversibility of RI and the safety of bortezomib come from studies that are heterogeneous with regard to patient selection criteria. Therefore, using a systematic approach we tried to address the still-controversial issue of the improvement of clinical outcome, if any, of MM patients with RI treated with bortezomib-based regimens.

\section{Materials and Methods}

A systematic and comprehensive search of the literature was performed using MEDLINE databases from 1978 to December 1, 2010, and a hand search of references. We used the following medical subject headings (MESH) to identify potential studies: 'myeloma renal failure' (1,225 hits) and 'bortezomib' (2,554 hits). An additional search performed by combining the MESH terms 'myeloma renal failure' and 'bortezomib' yielded 50 citations. Five additional case-control studies judged relevant for the purpose of study were also included [2, 3, 5, 7-9]. To minimize bias in the results, we restricted our eligibility criteria to studies available as full publications only. We did not include trials published in the form of an abstract because the quality of a trial cannot be judged from the abstract. Our search was also limited to papers published in English.

In total, 6 case reports, 9 cases series and 9 case-control studies were identified (fig. 1). For the purpose of this review, only case series and case-control studies were considered.
We formulated some key questions dealing with the demographic characteristics of the patients studied, the reversal of RI, and the doses and association of bortezomib therapy as well as toxicity.

It is worthy of note that due to heterogeneity in the design of several studies, mainly retrospective, and the inconsistency of reported data, we could not perform a meta-analysis.

\section{Patient Characteristics}

Demographic characteristics were available in 18 studies [1-18] accounting for 877 patients whose median age was 65 years (range 40-88) [1, 3, 5, 6, 8-11, 14, 15, 17, 18]. Gender, available in 12 studies, revealed a 1.02 male to female ratio $[1,3-6,10,11,14-18]$. Several patients (597 out of 877 , or $68 \%$ ) had relapsed/refractory MM, while the assessment of disease burden, performed according to Durie \& Salmon staging in 4 studies $[8,10,14,18]$ and to the International Staging System (ISS) in $5[2,4,5,15,16]$, revealed an advanced disease stage in the majority of patients. Accordingly, the percentage of patients in Durie and Salmon stage III ranged between 56 and 100\% (median 79\%), while patients in ISS stage III were between 21 and $100 \%$ (median $74 \%$ ).

\section{Definition and Assessment of RI}

Serum creatinine is the easiest method for assessing $\mathrm{RI}$ in MM. Accordingly, a serum creatinine higher than $2.0 \mathrm{mg} / \mathrm{dl}$ represents one of the hypercalcemia, RI, anemia and bone disease (CRAB) diagnostic criteria for symptomatic MM requiring therapy [19]. However, the serum creatinine level may depend on a number of factors such as age, sex and muscle mass. In this context, the glomerular filtration rate (GFR) appears to be a more accurate parameter, providing a true reflection of renal function. However, limitations in clinical practice in the use of either inulin or radiotracers have reduced its applicability.

The creatinine clearance $(\mathrm{CrCl})$ by timed (24-hour) urine collections has long been a mainstay in the assessment of renal function. Due to the additional tubular secretion of creatinine, a mechanism which becomes relatively more important when renal function declines, $\mathrm{CrCl}$ may overestimate GFR. In addition, based on $\mathrm{CrCl}$, a novel classification of chronic kidney disease has recently been produced (table 1) [20].

Serum creatinine concentration was used to assess the extent of $\mathrm{RI}$ in 6 studies $[8,10-14]$ and $\mathrm{CrCl}$ in 12 studies 
[1-7, 9, 15-18]. Interestingly, a growing use of $\mathrm{CrCl}$ characterizes studies published in the last few years.

Another relevant issue concerns the heterogeneity of the threshold selected to define RI. According to the arbitrary threshold chosen by different investigators, a $\mathrm{CrCl}$ value of $30 \mathrm{ml} / \mathrm{min}$ was used in 3 studies [4, 9, 17], $\mathrm{CrCl}$ ranged between 50 and $60 \mathrm{ml} / \mathrm{min}$ in 3 additional reports $[2,6,7]$, while $\mathrm{CrCl}$ cutoff was increased to $80 \mathrm{ml} /$ min in a single study [3].

Even the definition of the reversal of RI differs among various studies. In 5 reports, a generic definition of decreased creatinine levels is provided $[8,10,14,15,17]$, while in 2 studies the reversal of RI meets the criteria of a reduction of creatinine levels under $1.5 \mathrm{mg} / \mathrm{dl}[1,12]$. With the chronic kidney disease classification, new standards of improvement of renal function in MM have recently been proposed $[5,6]$. Renal complete response (CR renal) was defined as sustained (i.e. lasting at least 2 months) improvement of $\mathrm{CrCl}$ from lower than $50 \mathrm{ml} /$ $\mathrm{min}$ at baseline to $60 \mathrm{ml} / \mathrm{min}$. Renal partial response (PR renal) was defined as sustained improvement of $\mathrm{CrCl}$ from lower than 15 at baseline to $30-59 \mathrm{ml} / \mathrm{min}$. Renal minor response (MR renal) was defined as sustained improvement of baseline $\mathrm{CrCl}$ of lower than $15 \mathrm{ml} / \mathrm{min}$ to $15-29 \mathrm{ml} / \mathrm{min}$ or if baseline $\mathrm{CrCl}$ was $15-29 \mathrm{ml} / \mathrm{min}$, improvement to $30-59 \mathrm{ml} / \mathrm{min}$. This more accurate method to define the degree of reversal of RI has been used in more recently published studies [4-6, 16]. From a clinical standpoint, it helps to better assess the strength of renal response to therapy in comparison to criteria based only on serum creatinine measurements [20].

\section{Correlation of RI with Response and Clinical Outcome}

The pharmacokinetics of bortezomib are not affected by the degree of RI, as the primary metabolic pathway of bortezomib is the oxidative deboronation by cytochrome P450 [21]. On the other hand, studies indicate that bortezomib can produce improvement in renal function throughout NFKB inhibition $[3,5,6,14,17]$.

The rate of RI reversibility after treatment with bortezomib was addressed in 12 studies $[1,3-6,8,10,11$, 14-17] (table 2). It should be pointed out that the wide range of RI reversibility observed (16-85\%; median 41\%) reflects, at least in part, the heterogeneity of measurements. However, also when Ludwig et al. criteria [5] were applied, results did not change (i.e. CR renal ranged between 30 and 71\%). The heterogeneity of the patient co-
Table 1. Stage of RI

\begin{tabular}{llc}
\hline Stage & Description & $\begin{array}{l}\mathrm{GFR} \\
\mathrm{ml} / \mathrm{min} / 1.73 \mathrm{~m}^{2}\end{array}$ \\
\hline 1 & $\begin{array}{l}\text { kidney damage with normal } \\
\text { or elevated GFR }\end{array}$ & $\geq 90$ \\
\hline 2 & $\begin{array}{l}\text { kidney damage with mild } \\
\text { reduction of GFR }\end{array}$ & $60-89$ \\
\hline 3 & moderate reduction of GFR & $30-59$ \\
\hline 4 & severe reduction of GFR & $15-29$ \\
\hline 5 & renal failure & $\leq 15$ or on dialysis \\
\hline
\end{tabular}

Stage 5 is also defined as end-stage renal disease, while stage 4 is defined as pre-end-stage renal disease.

Table 2. Rate of reversal of RI

\begin{tabular}{|c|c|}
\hline Author & Reversal of RI, \% \\
\hline Roussou et al. [1] ${ }^{\mathrm{b}}$ & 40 \\
\hline Morabito et al. [3] ${ }^{\mathrm{d}}$ & 41 \\
\hline Roussou et al. [4] $]^{\mathrm{a}}$ & 71 \\
\hline Ludwig et al. [5] ${ }^{\mathrm{a}}$ & 62 \\
\hline Dimopoulos et al. [6] ${ }^{\mathrm{a}}$ & 41 \\
\hline Knauf et al. $[8]^{\mathrm{c}}$ & 85 \\
\hline Malani et al. $[10]^{\mathrm{c}}$ & 75 \\
\hline Chanan-Khan et al. [11] $]^{\mathrm{e}}$ & 16 \\
\hline Ludwig et al. $[14]^{\mathrm{c}}$ & 62 \\
\hline Li et al. $[15]^{\mathrm{c}}$ & 39 \\
\hline Dimopoulos et al. [16 ${ }^{\mathrm{a}}$ & 44 \\
\hline Qayum et al. $[17]^{\mathrm{c}}$ & 33 \\
\hline
\end{tabular}

hort and the retrospective character of several studies may account for these discrepancies $[4-6,16]$.

Some studies provide a comparison in terms of disease response between patients with RI and patients with normal renal function. Interestingly, the overall response rate after treatment with bortezomib was relatively high (table 3) and did not reflect the pretreatment renal status $[2,3,7,8,13,16]$; furthermore, results were similar when looking at the time to progression (TTP) $[2,7]$ or to progression-free survival [8]. 
Table 3. Response to bortezomib in patients with MM and RI

\begin{tabular}{lclc}
\hline Author & $\begin{array}{l}\text { Number } \\
\text { of patients }\end{array}$ & Disease status & $\begin{array}{l}\text { Overall response } \\
\text { rate, \% }\end{array}$ \\
\hline Roussou et al. [1] & 20 & upfront & 65 \\
San-Miguel et al. [2] & 203 & relapsed or refractory & 40 \\
Morabito et al. [3] & $27 / 90$ & upfront/relapsed or refractory & 66 \\
Roussou et al. [4] & 17 & upfront & 82 \\
Ludwig et al. [5] & $50 / 18$ & upfront/relapsed or refractory & 72 \\
Dimopoulos et al. [6] & $10 / 36$ & upfront/relapsed or refractory & 63 \\
Bladé et al. [7] & 193 & relapsed or refractory & 45 \\
Knauf et al. [8] & 14 & relapsed or refractory & 62 \\
Jagannath et al. [9] & 10 & relapsed or refractory & 30 \\
Malani et al. [10] & 4 & relapsed or refractory & 100 \\
Chanan-Khan et al. [11] & $1 / 23$ & upfront/relapsed or refractory & 75 \\
Kastritis et al. [12] & 2 & upfront & not available \\
Onitilo et al. [13] & 11 & upfront/relapsed or refractory & 68 \\
Ludwig et al. [14] & $7 / 1$ & upfront/relapsed or refractory & 62 \\
Li et al. [15] & 18 & upfront & 83 \\
Dimopoulos et al. [16] & 111 & upfront & 68 \\
Qayum et al. [17] & 6 & upfront/relapsed or refractory & 73 \\
Siniscalchi et al. [18] & 5 & upfront & 100 \\
\hline
\end{tabular}

In a subanalysis of the Study of Uncontrolled Multiple Myeloma Managed with Proteasome Inhibition Therapy (SUMMIT) and the Clinical Response and Efficacy Study of Bortezomib in the Treatment of Relapsing Multiple Myeloma (CREST) phase II, 3 of 10 patients (30\%) with $\mathrm{CrCl} \leq 30 \mathrm{ml} / \mathrm{min}$ demonstrated responses to treatment, compared with a $45 \%$ overall response rate in patients with baseline $\mathrm{CrCl}$ higher than $80 \mathrm{ml} / \mathrm{min}$ [9].

In a report of the phase III Assessment of Proteasome Inhibition for Extending Remissions (APEX) study of bortezomib versus high-dose dexamethasone, the efficacy and safety was assessed in patients with relapsed MM with varying degrees of RI. TTP, overall survival and safety were comparable between subgroups with $\mathrm{CrCl}$ $\leq 50 \mathrm{ml} / \mathrm{min}$ and $\mathrm{CrCl}$ higher than $50 \mathrm{ml} / \mathrm{min}$, although there was a trend toward shorter TTP and overall survival in patients with $\mathrm{CrCl} \leq 50 \mathrm{ml} / \mathrm{min}$ [2]. Similar results were observed in studies recently published by Morabito et al. [3] and Ludwig et al. [5].

Interestingly, when factors predictive of reversal of RI were sought, it was found that bortezomib-based regimens and $\mathrm{CrCl}$ higher than $30 \mathrm{ml} / \mathrm{min}$ were the only parameters independently associated with a higher probability of achieving renal response (PR or CR renal) [4].
More appealing were the results observed in patients treated upfront with bortezomib. In newly diagnosed patients who were not eligible for an autologous transplantation, Dimopoulos et al. [16] recently reported the results of the subgroup analysis of the Velcade as Initial Standard Therapy in Multiple Myeloma: Assessment with Melphalan and Prednisone (VISTA) phase III trial, regarding the effect of the VMP (bortezomib, melphalan, prednisone) combination on RI. Response rates were higher and both TTP and overall survival were longer with VMP versus melphalan and prednisone across renal cohorts. Reversal of RI, defined as a baseline eGFR lower than 50 improving to higher than $60 \mathrm{ml} / \mathrm{min}$, was seen in 49 of 111 (44\%) patients receiving VMP versus 40 of 116 (34\%) of those receiving melphalan and prednisone. Relatively younger age (i.e. $<75$ years) and eGFR $\geq 30 \mathrm{ml} / \mathrm{min}$ were independently associated with higher reversal rates. In both arms, rates of grade 4 and 5 adverse events appeared higher in patients with RI.

The time to reversal of RI after therapy with bortezomib, assessed in 10 reports, is also an important issue [1, $3-6,10,12,14-16]$. This time appears to be relatively short (median 1.4 months; range $0.5-3.7$ months) and led to the dialysis independence of 8 out of $32(25 \%)$ previously dialyzed patients $[3,5,6]$. 


\section{Dose and Schedule of Bortezomib}

Almost all patients were treated according to a standard schedule with a dose of $1.3 \mathrm{mg} / \mathrm{m}^{2}$ on days $1,4,8$ and 11 , repeated every 21 days $[1-10,12-16,18]$. Doses of bortezomib were reduced to $1.0 \mathrm{mg} / \mathrm{m}^{2}$ or even to 0.7 $\mathrm{mg} / \mathrm{m}^{2}$ in patients with grade $3-4$ nonhematologic toxicity [9]. In 3 patients [17], the bortezomib starting-dose was $1.0 \mathrm{mg} / \mathrm{m}^{2}$ because of poor performance status (ECOG 3-4) or a patient being older than 70 years, while in 4 patients, the reasons for the reduction of bortezomib doses were not specified [11-17].

Bortezomib was used alone [7-11, 14] or more frequently in association with dexamethasone $[1-6,8,10$ $15,17,18]$. Association with chemotherapy included Adriamycin [1, 5, 6, 14], epirubicin [15], pegylated liposomal doxorubicin [7] and melphalan [16]. Finally, either thalidomide $[1,6,11,12]$ or lenalidomide [6] were associated with bortezomib in some recently published reports.

\section{Toxicity}

Adverse events and side effects were generally described in all 18 studies considered in the present analysis [1-18]. A predominance of peripheral neuropathy and thrombocytopenia was found. Remarkably, toxicity was generally found comparable in 5 studies including $M M$ patients with and without renal failure $[1-4,9]$. The rate of grade 3-4 thrombocytopenia was higher in the subset of patients who had renal failure in the study by Jagannath et al. [9]. When a different pattern of toxicity was observed in relation to the status of renal function, the rate of discontinuation of therapy was similar [16].

\section{Conclusions}

Despite the paucity of data, it is important to note that this article represents the first systematic review of the entire body of available clinical evidence dealing with the use of bortezomib in MM patients with RI.

The following conclusions could be drawn from the studies analyzed in this review: (1) bortezomib is feasible and well tolerated, and its efficacy and safety are not substantially modified by renal failure patients, (2) renal failure should not induce physicians to reduce doses, since the efficacy of bortezomib is maintained also in dialyzed patients who may achieve dialysis independence, and (3) standard doses of bortezomib (i.e. $1.3 \mathrm{mg} / \mathrm{m}^{2}$ on days 1 , 4,8 and 11) associated with dexamethasone yield a satisfactory tumor response rate, generally obtained in a short period of time.

Whether different schedules of bortezomib based on a weekly administration [22] might be successfully used in MM patients with RI is so far not clear. This approach could be interesting in limiting the two main side effects of the drug, namely thrombocytopenia and peripheral neuropathy. Likewise, the value of a maintenance therapy with bortezomib in responding patients who do not achieve reversal of RI should be carefully evaluated.

\section{References}

1 Roussou M, Kastritis E, Migkou M, Psimenou E, Grapsa I, Matsouka C, Barmparousi D, Terpos E, Dimopoulos MA: Treatment of patients with multiple myeloma complicated by renal failure with bortezomib-based regimens. Leuk Lymphoma 2008;49:890-895.

-2 San-Miguel JF, Richardson PG, Sonneveld P, Schuster MW, Irwin D, Stadtmauer EA, Facon T, Harousseau JL, Ben-Yehuda D, Lonial S, Goldschmidt H, Reece D, Bladé J, Boccadoro M, Cavenagh JD, Neuwirth R, Boral AL, Esseltine DL, Anderson KC: Efficacy and safety of bortezomib in patients with renal impairment: results from the APEX phase 3 study. Leukemia 2008;22:842-849.
3 Morabito F, Gentile M, Ciolli S, Petrucci MT, Galimberti S, Mele G, Casulli AF, Mannina D, Piro E, Pinotti G, Palmieri S, Catalano L, Callea V, Offidani M, Musto P, Bringhen S, Baldini L, Tosi P, Di Raimondo F, Boccadoro M, Palumbo A, Cavo M: Safety and efficacy of bortezomib-based regimens for multiple myeloma patients with renal impairment: a retrospective study of Italian Myeloma Network GIMEMA. Eur J Haematol 2010;84: 223-228.

-4 Roussou M, Kastritis E, Christoulas D, Migkou M, Gavriatopoulou M, Grapsa I, Psimenou E, Gika D, Terpos E, Dimopoulos MA: Reversibility of renal failure in newly diagnosed patients with multiple myeloma and the role of novel agents. Leuk Res 2010; 34:1395-1397. $\checkmark 5$ Ludwig H, Adam Z, Hajek R, Greil R, Tóthová E, Keil F, Autzinger EM, Thaler J, Gisslinger H, Lang A, Egyed M, Womastek I, Zojer N: Light chain-induced acute renal failure can be reversed by bortezomib-doxorubicin-dexamethasone in multiple myeloma: results of a phase II study. J Clin Oncol 2010;28:4635-4641.

6 Dimopoulos MA, Roussou M, Gavriatopoulou M, Zagouri F, Migkou M, Matsouka C, Barbarousi D, Christoulas D, Primenou E, Grapsa I, Terpos E, Kastritis E: Reversibility of renal impairment in patients with multiple myeloma treated with bortezomib-based regimens: identification of predictive factors. Clin Lymphoma Myeloma 2009;9:302306. 
7 Bladé J, Sonneveld P, San Miguel JF, Sutherland HJ, Hajek R, Nagler A, Spencer A, Robak T, Cibeira MT, Zhuang SH, Harousseau JL, Orlowski RZ, DOXIL-MMY-3001 Study Investigators: Pegylated liposomal doxorubicin plus bortezomib in relapsed or refractory multiple myeloma: efficacy and safety in patients with renal function impairment. Clin Lymphoma Myeloma 2008;8:352-355.

-8 Knauf WU, Otremba B, Overkamp F, Kornacker M: Bortezomib in relapsed multiple myeloma: results of a non-interventional study by office-based haematologists. Onkologie 2009;32:175-180.

$\checkmark 9$ Jagannath S, Barlogie B, Berenson JR, Singhal S, Alexanian R, Srkalovic G, Orlowski RZ, Richardson PG, Anderson J, Nix D, Esseltine DL, Anderson KC, SUMMIT/CREST Investigators: Bortezomib in recurrent and/ or refractory multiple myeloma: initial clinical experience in patients with impaired renal function. Cancer 2005;103:1195-1200.

-10 Malani AK, Gupta V, Rangineni R: Bortezomib and dexamethasone in previously untreated multiple myeloma associated with renal failure and reversal of renal failure. Acta Haematol 2006;116:255-258.

- 11 Chanan-Khan AA, Kaufman JL, Mehta J, Richardson PG, Miller KC, Lonial S, Munshi NC, Schlossman R, Tariman J, Singhal S: Activity and safety of bortezomib in multiple myeloma patients with advanced renal failure: a multicenter retrospective study. Blood 2007;109:2604-2606.
12 Kastritis E, Anagnostopoulos A, Roussou M, Gika D, Matsouka C, Barmparousi D, Grapsa I, Psimenou E, Bamias A, Dimopoulos MA: Reversibility of renal failure in newly diagnosed multiple myeloma patients treated with high dose dexamethasone-containing regimens and the impact of novel agents. Haematologica 2007;92:546-549.

13 Onitilo AA, Engel J, Olatosi B, Fagbemi S: Community experience with bortezomib in patients with multiple myeloma. Am J Hematol 2007;82:637-639.

14 Ludwig H, Drach J, Graf H, Lang A, Meran JG: Reversal of acute renal failure by bortezomib-based chemotherapy in patients with multiple myeloma. Haematologica 2007;92: 1411-1414.

15 Li J, Zhou DB, Jiao L, Duan MH, Zhang W, Zhao YQ, Shen T: Bortezomib and dexamethasone therapy for newly diagnosed patients with multiple myeloma complicated by renal impairment. Clin Lymphoma Myeloma 2009;9:394-398.

16 Dimopoulos MA, Richardson PG, Schlag R, Khuageva NK, Shpilberg O, Kastritis E, Kropff M, Petrucci MT, Delforge M, Alexeeva J, Schots R, Masszi T, Mateos MV, Deraedt $W$, Liu $K$, Cakana $A$, van de Velde $H$, San Miguel JF: VMP (Bortezomib, Melphalan, and Prednisone) is active and well tolerated in newly diagnosed patients with multiple myeloma with moderately impaired renal function, and results in reversal of renal impairment: cohort analysis of the phase III VISTA study. J Clin Oncol 2009;27:60866093.

17 Qayum A, Aleem A, Al Diab AR, Niaz F, Al Momen AK: Rapid improvement in renal function in patients with multiple myeloma and renal failure treated with bortezomib. Saudi J Kidney Dis Transpl 2010;21:63-68.
18 Siniscalchi A, Dentamaro T, Perrotti A, Tatangelo P, de Fabritiis P, Caravita T: Bortezomib-based therapy as induction regimen of an autograft program in front-line treatment of multiple myeloma with endstage renal disease. Ann Hematol 2010;89: 821-822.

$>19$ International Myeloma Working Group: Criteria for the classification of monoclonal gammopathies, multiple myeloma and related disorders: a report of the International Myeloma Working Group. Br J Haematol 2003;121:749-757.

20 Dimopoulos MA, Terpos E, Chanan-Khan A, Leung N, Ludwig H, Jagannath S, Niesvizky R, Giralt S, Fermand J-P, Bladé J, Comenzo RL, Sezer O, Palumbo A, Harousseau J-L, Richardson PG, Barlogie B, Anderson KC, Sonneveld P, Tosi P, Cavo M, Rajkumar SV, Durie BGM, Miguel JS: Renal impairment in patients with multiple myeloma: a consensus statement on behalf of the International Myeloma Working Group. J Clin Oncol 2010;28:4976-4984.

21 Uttamsingh V, Lu C, Miwa G, Gan LS: Relative contributions of the five major human cytochromes P450, 1A2, 2C9, 2C19, 2D6, and $3 \mathrm{~A} 4$, to the hepatic metabolism of the proteasome inhibitor bortezomib. Drug Metab Dispos 2005;33:1723-1728.

$>22$ Bringhen S, Larocca A, Rossi D, Cavalli M, Genuardi M, Ria R, Gentili S, Patriarca F, Nozzoli C, Levi A, Guglielmelli T, Benevolo G, Callea V, Rizzo V, Cangialosi C, Musto P, De Rosa L, Liberati AM, Grasso M, Falcone AP, Evangelista A, Cavo M, Gaidano G, Boccadoro M, Palumbo A: Efficacy and safety of once-weekly bortezomib in multiple myeloma patients. Blood 2010;116:4745-4753. 